He offers, for the benefit of psychiatrists and of their colleagues in medicine, social work and allied fields, a concise history of recent developments in psychiatric education and psychiatric practice, together with an appraisal of its present status. He goes on to indicate a number of important psychiatric problems which are still quite imperfectly dealt with; these include the prevalence of minor emotional illnesses, and the unsolved questions of how best to deal with disorders of personality, drop-outs, drug addicts and vagrants.

A particularly interesting chapter is entitled "Patterns between care based on the district general hospital (as is widely practised in the Manchester Region), a service in Plymouth based on a mental health centre, and the clinical work of the academic department of psychiatry in the Middlesex Hospital, London. Not surprisingly, there were striking differences both in terms of clinical staffing and of the patient clientèle in each of these three services. The claims of the "Lancastrian movement" of general-hospital based psychiatrists to be able to cope with all the psychiatric problems of their populations are sympathetically considered; but the figures in his Tables 5.1 and 5.2 show very clearly that the staffing of these psychiatric units is so meagre that they are obliged to concentrate on the treatment of acute psychotic and psycho-geriatric cases. With the best will in the world, they cannot offer appropriate care to more than a very small fraction of the nourotics, the disturbed adolescents, and the patients with major personality disorders in their respective catchment areas.

This short monograph offers to any interested reader a brief, authoritative conspectus of the state of psychiatric teaching and practice in Britain in 1969. As such, it may also serve as a useful point of reference for comparison in years to come.

G. M. Carstatrus of Psychiatric Care". Here, comparisons are drawn

generations of students of zoology. His approach is from first biological principles. He takes as his starting point the fact that in any circulatory system, fluid which passes from it to the tissues must, of necessity, eventually pass back again; thus after considering the lymphatic system of man as a fully formed system, he takes his readers back to the beginning and reviews the circulatory systems of the invertebrates. It is here that one begins to appreciate, both the width and the depth of the author's interest; the subsequent chapters in which the chordate lymphatic system is dealt with in detail confirm one's first impressions of the scholarly nature of the whole book.

Some, perhaps most readers, will consider the author's style of writing as somewhat old-fashioned and leisurely, but it does make a most readable book and his many asides in which he comments on matters which at first glance are a little removed from the main argument are all deeply considered and are usually thought provoking. We are presented with not only a first class work of reference to what is known of the lymphatic system but a most readable text in which the comparative morphology of the vertebrate lymphatic system is presented in an evolutionary context in which full regard has been paid to the modern views on the course of vertebrate evolution.

The book is produced and illustrated to a very high standard, but it is regrettable that after my praise of its contents it is necessary to comment that the final proof reading has permitted a large number of mis-spellings to persist (sometimes the same word, usually a generic name, is spelt in two ways on the same page). There are also instances of broken type, and the setting of the type in two columns to each page has necessitated many words being hyphenated at the end of a line and this has often been done with little regard for sense; "lymphaticovenous" (sic) is one of the stranger examples. But this criticism should not detract from the worth of a contribution of considerable biological scholarship. G. E. H. Foxon

\section{NUTRITION IN CHILDREN}

\section{Evolution and Comparative Morphology of the Lymphatic System}

By Otto Frederic Kampmeier. Pp. xiv + 620. (Charles C. Thomas: Springfield, Illinois, October 1969.) $\$ 29.50$.

Alx who have undertaken a course in animal biology are aware of the existence of the lymphatic system; but the amount that is generally known about its occurrence and extent is probably more limited than is the knowledge of any other "system" of the vertebrate body. Students of zoology usually meet, quite early in their course, the large lymph spaces beneath the skin of frogs; they are also told of the function of the lymphatics in the transport of ingested fat and may see lacteals in histological sections; they hear of the presence of the thoracic duct in mammals and probably see lymph nodes in dissecting the neck of the rat. There must be few students of zoology whose acquaintance with the lymph system is more extensive. Human anatomists know, of course, very considerably more of the lymphatic system of man; the lymphatic pathway for the spread of infective agents and neoplasms is highly important clinically. The trouble with the lymphatic system is the impossibility of displaying it in dissection without laborious and time-consuming prepara. tion. This book should serve not only to remove much of our ignorance of the anatomy and morphology of this system but encourage us to take a much more lively interest in it.

Professor Kampmeier has devoted a lifetime of study to the lymphatic system and he has now provided not only an authoritative account of it throughout the animal kingdom but has shown that in vertebratcs it possesses a comparative morphology as significant as that of the rest of the circulatory system-the arteries and veins which have been studied in a comparative manner by many
(Symposia of the Swedish Nutrition Foundation, VII.) Edited by Gunnar Blix. Pp. 154. (Almqvist and Wiksell: Stockholm, 1969.) $45 \mathrm{Sw} . \mathrm{kr}$.

THIs publication contains the papers presented at a symposium of the Swedish Nutrition Foundation which was hold in Sweden in August 1968. The symposium was attended by many eminent nutritionists and physicians who were interested in nutrition and growth in the preschool and school age groups. The results of the sym. posium are presented as a series of papers, each one being followed by a brief account of the discussion which took place.

In the first chapter, Professor Tanner presents an to adolescence, and illustrates the importance of longitudinal growth velocity studies showing the tremendous variation which can occur particularly around the period of puberty. 'This interesting chapter concludes with an account of the secular trend over the last century, illustrating how in most countries height has been increasing while maturity has been occurring earlier and earlier. Following this excellent and general introduction, successive chapters deal with the effect of nutrition on cellular growth following which the body composition during growth is discussed, and then the application of modern knowledge of nutrition to various groups of children takes up most of the rest of the book.

Two interesting chapters concern the effect of malnutrition on physical and intellectual development. The investigators seem to prove that malnutrition has a permanent effect on physical and intellectual development

\section{Nutrition in Preschool and School Age} interesting summary of the pattern of growth from birth in many children, but, particularly when considering the 